\title{
Low 1,5-anhydroglucitol levels are associated with long-term cardiac mortality in acute coronary syndrome patients with hemoglobin A1c levels less than $7.0 \%$
}

\author{
Shohei Ouchi", Kazunori Shimada*, Tetsuro Miyazaki, Shuhei Takahashi, Yurina Sugita, Megumi Shimizu, \\ Azusa Murata, Tomoyasu Kadoguchi, Takao Kato, Tatsuro Aikawa, Shoko Suda, Eiryu Sai, Masaru Hiki, \\ Hiroshi Iwata, Takatoshi Kasai, Katsumi Miyauchi and Hiroyuki Daida
}

\begin{abstract}
Background: Diabetes mellitus is considered an important risk factor for cardiovascular diseases. High hemoglobin A1c (HbA1c) levels, which indicate poor glycemic control, have been associated with occurrence of cardiovascular diseases. There are few parameters which can predict cardiovascular risk in patients with well-controlled diabetes. Low 1,5-anhydroglucitol (1,5-AG) levels are considered a clinical marker of postprandial hyperglycemia. We hypothesized that low 1,5-AG levels could predict long-term mortality in acute coronary syndrome (ACS) patients with relatively low HbA1c levels.

Methods: The present study followed a retrospective observational study design. We enrolled 388 consecutive patients with ACS admitted to the cardiac intensive care unit at the Juntendo University Hospital from January 2011 to December 2013. Levels of 1,5-AG were measured immediately before emergency coronary angiography. Patients with early stent thrombosis, no significant coronary artery stenosis, malignancy, liver cirrhosis, a history of gastrectomy, current steroid treatment, moderately to severely reduced kidney function (estimated glomerular filtration rate $<45 \mathrm{ml} / \mathrm{min} / 1.73 \mathrm{~m}^{2}$; chronic kidney disease stage $3 \mathrm{~B}, 4$, and 5), HbA1c levels $\geq 7.0 \%$, and those who received sodium glucose co-transporter 2 inhibitor therapy were excluded.

Results: During the 46.9-month mean follow-up period, nine patients (4.5\%) died of cardiovascular disease. The 1,5AG level was significantly lower in the cardiac death group compared with that in the survivor group (12.3 $\pm 5.3 \mathrm{vs}$. $19.2 \pm 7.7 \mu \mathrm{g} / \mathrm{ml}, p<0.01$ ). Kaplan-Meier survival analysis showed that low 1,5-AG levels were associated with cardiac mortality $(p=0.02)$. Multivariable Cox regression analysis showed that 1,5-AG levels were an independent predictor of cardiac mortality (hazard ratio $0.76 ; 95 \%$ confidence interval $0.41-0.98 ; p=0.03$ ).
\end{abstract}

Conclusion: Low 1,5-AG levels, which indicate postprandial hyperglycemia, predict long-term cardiac mortality even in ACS patients with HbA1c levels $<7.0 \%$.

Keywords: 1,5-anhydroglucitol, Diabetes mellitus, Postprandial hyperglycemia, Acute coronary syndrome, Cardiac mortality

\section{Background}

Diabetes mellitus (DM) is considered an important risk factor for cardiovascular disease, including acute coronary syndrome (ACS), and death [1-5].

*Correspondence: uchi@juntendo.ac.jp; shimakaz@juntendo.ac.jp Department of Cardiovascular Medicine, Juntendo University Graduate School of Medicine, 2-1-1 Hongo Bunkyo-ku, Tokyo 113-8421, Japan
High hemoglobin A1c (HbA1c) levels, which indicate poor glycemic control, have been associated with poor prognosis in patients with diabetes mellitus [6-10]. Treatment of DM is performed using $\mathrm{HbA} 1 \mathrm{c}$ as an indicator, and an HbA1c level $<7.0 \%$ is the recommended target for adult patients as per the American Diabetes Association and the 
European Association for the Study of Diabetes $[11,12]$. However, previous studies have shown that atherosclerosis is pre-existent even at a stage when impaired glucose tolerance and postprandial hyperglycemia are detected [13-15]. Indeed, numerous studies have reported cardiovascular diseases, including ACS, in patients with HbA1c $<7.0 \%$ [13-16].

1,5-Anhydroglucitol (1,5-AG) is a monosaccharide found in most foods [17]. The concentration of 1,5-AG in blood and tissues is maintained constant due to reabsorption in the renal proximal tubule $[17,18]$. As excretion of glucose into the urine increases, reabsorption of 1,5-AG is inhibited competitively and the blood level of 1,5-AG decreases. Therefore, low 1,5-AG levels in blood are considered a clinical marker of postprandial hyperglycemia $[19,20]$.

There are few parameters which can predict cardiovascular risk in patients with well-controlled diabetes and/or with relatively low HbA1c levels. We and other groups have reported that 1,5-AG levels are associated with atherosclerotic disease, including coronary artery disease and risk of revascularization after elective percutaneous coronary intervention [20-23]. Therefore, we hypothesized that low 1,5-AG levels could predict longterm mortality in ACS patients with relatively low HbA1c levels.

\section{Methods}

\section{Patients}

The present study was conducted as a retrospective observational study. All subjects gave their informed consent for inclusion before they participated in the study. The study was conducted in accordance with the Declaration of Helsinki and the protocol was approved by the Ethics Committee of Juntendo University Hospital. First, we recruited 388 consecutive patients with ACS admitted to the cardiac intensive care unit at the Juntendo University Hospital between January 2011 and December 2013. Patients with early stent thrombosis (occurring $0-30$ days post stent implantation) [24], no significant coronary artery stenosis, malignancy, liver cirrhosis, a history of gastrectomy, current steroid treatment, moderately to severely impaired kidney function (defined as an estimated glomerular filtration rate (eGFR) of $<45 \mathrm{ml} / \mathrm{min} / 1.73 \mathrm{~m}^{2}$; chronic kidney disease stage 3B, 4, and 5 [25]), HbA1c levels $\geq 7.0 \%$, and those under treatment with sodium-glucose co-transporter 2 inhibitors were excluded from the study. Study subject selection is depicted in Fig. 1.

\section{Definitions}

ACS was defined as presence of unstable angina pectoris, non-ST elevation myocardial infarction, or ST elevation myocardial infarction. Unstable angina pectoris was defined as angina at rest or in an accelerating

\section{8 patients with acute coronary syndrome admitted to the CICU in Juntendo University Hospital from January 2011 to December 2013}

190 patients were excluded 36 patients with normal coronary artery 1 patients with subacute thrombosis 20 patients with malignant disease 2 patients with liver cirrhosis 4 patients having a history of gastrectomy 8 patients taking steroids 58 patients with chronic kidney disease $($ eGFR $<45)$ 17 patients not measured $1,5 \mathrm{AG}$ 44 patients with $\mathrm{HbA} 1 \mathrm{c} \geq 7.0 \%$

198 patients

Fig. 1 Flow diagram of the study subjects 
pattern with negative cardiac biomarkers with or without ECG changes indicative of myocardial ischemia (ST segment depression or transient elevation or new $\mathrm{T}$ wave inversion) [26]. Non-ST elevation myocardial infarction was defined as an increase ( $\geq 2$-fold) in serum creatine kinase, and troponin T positivity, without ECG changes of persistent ST-elevation [26]. ST elevation myocardial infarction was defined as an increase ( $\geq 2$-fold) in serum creatine kinase, and troponin $\mathrm{T}$ positivity, with ECG changes of persistent ST-elevation [27]. There were 59 patients with unstable angina pectoris, 53 patients with non-ST elevation myocardial infarction, and 86 patients with ST elevation myocardial infarction. Cardiac death was defined as death due to cardiovascular disease (e.g., heart failure, myocardial infarction, sudden death). Multi-vessel coronary disease was defined as presence of coronary artery disease of two or more vessels with visually assessed stenosis of more than $75 \%$ based on the American Heart Association Classification [28, 29]. DM was defined as presence of a previous diagnosis in medical records, HbA1c levels of $\geq 6.5 \%$, or treatment with oral anti-diabetic agents or insulin. Dyslipidemia was defined as presence of a previous diagnosis in medical records, abnormal lipid profiles (i.e., triglyceride levels $\geq 150 \mathrm{mg} / \mathrm{dl}$, low-density lipoprotein cholesterol levels $\geq 140 \mathrm{mg} / \mathrm{dl}$, or high-density lipoprotein cholesterol levels $\leq 40 \mathrm{mg} / \mathrm{dl}$ ), or treatment with anti-dyslipidemic agents. Hypertension was defined as presence of a previous diagnosis due to systolic blood pressure $\geq 140 \mathrm{mmHg}$ and/or diastolic blood pressure $\geq 90 \mathrm{mmHg}$ in medical records, or treatment with anti-hypertensive agents [30].

\section{Data collection and blood sampling}

Clinical findings including age, gender, body mass index, smoking, family history of coronary artery disease, blood pressure, heart rate, left ventricular ejection fraction, and medical history of DM, dyslipidemia, hypertension, atrial fibrillation, and revascularization were collected on admission. Laboratory findings of total cholesterol, triglycerides, high-density lipoprotein cholesterol, lowdensity lipoprotein cholesterol, eGFR, brain natriuretic peptide, albumin, hemoglobin, and HbA1c were obtained after an overnight fast, within $24 \mathrm{~h}$ of admission. The eGFR was calculated using the Japanese equation comprising the serum creatinine level, age, and gender as follows: eGFR $\left(\mathrm{ml} / \mathrm{min} / 1.73 \mathrm{~m}^{2}\right)=194 \times$ creatinine ${ }^{-1.094} \times$ age $^{-0.287}$ (for females, $\times 0.739$ ) [31]. Plasma total cholesterol and creatinine levels were measured using enzymatic methods, triglyceride levels using visible absorption spectrometry, high-density lipoprotein cholesterol levels using the direct method, and lowdensity lipoprotein cholesterol levels were calculated using the Friedewald formula [32]. Brain natriuretic peptide levels were measured using the one-step sandwich enzyme immunoassay method, albumin levels using the bromocresol purple method, hemoglobin levels using the cyanmethemoglobin method, and HbA1c levels using high-performance liquid chromatography. Blood samples were obtained immediately prior to coronary angiography and stored at $-80^{\circ} \mathrm{C}$ until measurement of 1,5-AG levels. Serum 1,5-AG levels were measured with a colorimetric method (Nippon Kayaku, Tokyo, Japan) using a Lana 1,5-AG auto liquid automatic analyzer (JCA-BM 8060, JEOL Ltd., Tokyo, Japan).

\section{Angiographical analysis}

Coronary artery angiography was performed in all patients during hospitalization. We performed angiographical analysis for all patients in order to evaluate coronary artery disease and/or thromboembolic disorders. Significant stenosis was defined as a decrease in the pre-stenotic diameter of the blood vessels $>75 \%$ in the left anterior descending coronary artery, left circumflex coronary artery, and right coronary artery, and $>50 \%$ in the left main coronary trunk. Quantitative coronary angiography was performed in all subjects, and analyses were performed by a technician without any knowledge of the study design [33]. All treatment decisions including use of bare metal stents, drug eluting stents, or balloon alone for percutaneous coronary intervention, and choice of coronary artery bypass grafting or drug therapy alone were made at the discretion of the physician.

\section{Statistical analysis}

Continuous variables were represented as means with standard deviations, and categorical variables were represented as counts and percentages. Comparisons of continuous variables were performed using the Student's $t$-test or the Mann-Whitney $U$ test. Categorical variables were analyzed using the Chi squares test or the Fisher's exact probability test. Unadjusted cumulative event rate for the primary endpoint was estimated using the Kaplan-Meier method and was compared between groups using the log-rank test. The cut-off value was defined using the median of the 1,5-AG level $(18.5 \mu \mathrm{g} /$ $\mathrm{ml})$. Univariate and multivariate Cox regression analyses were performed to identify the predictor of the primary endpoint. Hazard ratios (HRs) and 95\% confidence intervals (CIs) were also calculated. Age, gender, body mass index, and all variables with a $p$-value $<0.1$ in univariate Cox regression analysis were included in the multivariate analyses. JMP12 (for Windows, SAS Institute, Cary, NC) was used for statistical analyses, and $p$-values $<0.05$ were considered statistically significant. 


\section{Results}

Of the 388 patients enrolled in the study, 198 patients were examined. The mean patient age was $65 \pm 12$ years and 164 patients $(82.8 \%)$ were male. The patients were followed up until December 2016. The mean follow-up duration was $46.9 \pm 16.9$ months, and the maximum follow-up duration was 72.7 months. During follow-up, 9 patients $(4.5 \%)$ had cardiovascular death (sudden death: 4 patients, heart failure: 5 patients). These death events were retrieved from the hospital medical records. The patients were categorized into the survivor group or the cardiac death group. Patient characteristics and laboratory findings are shown in Table 1. The 1,5-AG level was significantly lower in the cardiac death group than in the survivor group $(12.3 \pm 5.3$ vs. $19.2 \pm 7.7 \mu \mathrm{g} / \mathrm{ml}$, $p<0.01$ ). Patients in the cardiac death group were significantly older, had lower levels of left ventricular ejection fraction, albumin, and hemoglobin, and had significantly higher levels of brain natriuretic peptide and HbA1c than those in the survivor group ( $p<0.05$ in all comparisons).

Affected coronary artery status, treatment strategy, and pharmacological therapy at discharge are shown at Table 2. Diuretic administration at discharge was significantly more common in the cardiac death group than in the survivor group $(p=0.03)$.

In this study population, the 1,5-AG level was negatively related to age, brain natriuretic peptide level, and HbA1c level ( $p<0.05$ in all comparisons). Furthermore, 1,5-AG levels were significantly lower in patients with $\mathrm{DM}$, hypertension, multi-vessel disease, left main coronary trunk lesions, or anti-platelet or oral hypoglycemic agent administration at discharge, than in their counterparts ( $p<0.05$ in all comparisons). The 1,5-AG levels were significantly higher in current smokers than nonsmokers $(p=0.02)$.

Kaplan-Meier analysis was performed to estimate the unadjusted event-free rate of cardiac death. Patients were

Table 1 Patient characteristics and laboratory findings at hospitalization

\begin{tabular}{|c|c|c|c|}
\hline & Survivor group $(n=189)$ & cardiac death group $(n=9)$ & $p$-value* \\
\hline Age (years) & $65 \pm 12$ & $75 \pm 12$ & $<0.01$ \\
\hline Male, n (\%) & $156(82.5)$ & $8(88.9)$ & NS \\
\hline Body mass index $\left(\mathrm{kg} / \mathrm{m}^{2}\right)$ & $24.3 \pm 3.3$ & $22.4 \pm 2.4$ & NS \\
\hline Diabetes mellitus, n (\%) & $34(18.0)$ & $3(33.3)$ & NS \\
\hline Dyslipidemia, n (\%) & $152(80.4)$ & $7(77.8)$ & NS \\
\hline Hypertension, n (\%) & $103(54.5)$ & $5(55.6)$ & NS \\
\hline Current smoker, n (\%) & $63(33.3)$ & $1(11.1)$ & NS \\
\hline Family history of CAD, n (\%) & $58(30.7)$ & $1(11.1)$ & NS \\
\hline Atrial fibrillation, n (\%) & $18(9.5)$ & $2(22.2)$ & NS \\
\hline \multicolumn{4}{|l|}{ History of revascularization } \\
\hline $\mathrm{PCl}, \mathrm{n}(\%)$ & $31(16.4)$ & $1(11.1)$ & NS \\
\hline CABG, n (\%) & $7(3.7)$ & $0(0.0)$ & NS \\
\hline Systolic blood pressure (mmHg) & $139 \pm 26$ & $139 \pm 36$ & NS \\
\hline Diastolic blood pressure $(\mathrm{mmHg})$ & $79 \pm 19$ & $79 \pm 24$ & NS \\
\hline Heart rate (/min) & $77 \pm 17$ & $88 \pm 24$ & NS \\
\hline LVEF (\%) & $56.6 \pm 11.7$ & $47.7 \pm 14.0$ & 0.03 \\
\hline Total cholesterol (mg/dl) & $187 \pm 43$ & $168 \pm 43$ & NS \\
\hline Triglycerides (mg/dl) & $137 \pm 95$ & $108 \pm 33$ & NS \\
\hline HDL-cholesterol (mg/dl) & $46 \pm 12$ & $41 \pm 15$ & NS \\
\hline LDL-cholesterol (mg/dl) & $115 \pm 39$ & $105 \pm 28$ & NS \\
\hline $\mathrm{eGFR}\left(\mathrm{ml} / \mathrm{min} / 1.73 \mathrm{~m}^{2}\right)$ & $81.3 \pm 20.4$ & $68.1 \pm 17.2$ & NS \\
\hline Brain natriuretic peptide $(\mathrm{pg} / \mathrm{ml})$ & $151 \pm 345$ & $597 \pm 882$ & 0.03 \\
\hline Albumin $(\mathrm{g} / \mathrm{dl})$ & $4.0 \pm 0.5$ & $3.6 \pm 0.7$ & 0.01 \\
\hline Hemoglobin (g/dl) & $14.5 \pm 1.7$ & $13.0 \pm 2.3$ & 0.01 \\
\hline Hemoglobin A1c (\%) & $5.8 \pm 0.5$ & $6.2 \pm 0.6$ & 0.02 \\
\hline $1,5-\mathrm{AG}(\mu \mathrm{g} / \mathrm{ml})$ & $19.2 \pm 7.7$ & $12.3 \pm 5.3$ & $<0.01$ \\
\hline
\end{tabular}

Data are presented as mean \pm standard deviation, or number (percentage)

$C A D$ coronary artery disease, $P C I$ percutaneous coronary intervention, $C A B G$ coronary artery bypass grafting, $L V E F$ left ventricular ejection fraction, $H D L$ high-density lipoprotein, $L D L$ low-density lipoprotein, eGFR estimated glomerular filtration rate, 1,5-AG 1,5-anhydroglucitol

* Comparisons between the survivor and the cardiac death groups 
Table 2 Affected coronary artery status, treatment strategy, and pharmacological therapy at discharge

\begin{tabular}{|c|c|c|c|}
\hline & Survivor group $(n=189)$ & Cardiac death group $(n=9)$ & $p$-value* \\
\hline Number of diseased vessel & & & NS \\
\hline One, n (\%) & $80(42.3)$ & $2(22.2)$ & \\
\hline Two, n (\%) & $54(28.6)$ & $3(33.3)$ & \\
\hline Three, n (\%) & $55(29.1)$ & $4(44.5)$ & \\
\hline Stenosis of LMT, n (\%) & $15(7.9)$ & $2(22.2)$ & NS \\
\hline Multi-vessel, n (\%) & $112(59.3)$ & $8(88.9)$ & NS \\
\hline Target lesion & & & NS \\
\hline LAD, n (\%) & $97(51.3)$ & $4(44.5)$ & \\
\hline LCX, n (\%) & $32(16.9)$ & $0(0.0)$ & \\
\hline $\mathrm{RCA}, \mathrm{n}(\%)$ & $53(28.1)$ & $3(33.3)$ & \\
\hline LMT, n (\%) & $7(3.7)$ & $2(22.2)$ & \\
\hline Treatment strategy & & & NS \\
\hline $\mathrm{PCl}(\mathrm{BMS}), \mathrm{n}(\%)$ & $82(43.4)$ & $4(44.5)$ & \\
\hline $\mathrm{PCl}(\mathrm{DES}), \mathrm{n}(\%)$ & $64(33.9)$ & $3(33.3)$ & \\
\hline POBA, n (\%) & $14(7.4)$ & $0(0.0)$ & \\
\hline CABG, n (\%) & $12(6.3)$ & $1(11.1)$ & \\
\hline \multicolumn{4}{|l|}{ Pharmacological therapy at discharge } \\
\hline Diuretics, n (\%) & $39(20.6)$ & $5(55.6)$ & 0.03 \\
\hline Anti-platelets, n (\%) & $188(99.5)$ & $9(100)$ & NS \\
\hline Anti-coagulants, n (\%) & $15(7.9)$ & $2(22.2)$ & NS \\
\hline CE inhibitor or ARB, n (\%) & $134(70.9)$ & $7(77.8)$ & NS \\
\hline Beta-blocker, n (\%) & $133(70.4)$ & $6(66.7)$ & NS \\
\hline Calcium-channel blocker, n (\%) & $52(27.5)$ & $1(11.1)$ & NS \\
\hline Statin, n (\%) & $171(90.5)$ & $6(66.7)$ & NS \\
\hline Oral hypoglycemic agents, n (\%) & $20(10.6)$ & $2(22.2)$ & NS \\
\hline Sulfonylurea, n (\%) & $5(2.7)$ & $1(11.1)$ & NS \\
\hline Alpha-glucosidase inhibitor, n (\%) & $9(4.8)$ & $0(0.0)$ & NS \\
\hline DPP-4 inhibitor, n (\%) & $8(4.2)$ & $2(22.2)$ & NS \\
\hline Metformin, n (\%) & $4(2.1)$ & $0(0.0)$ & NS \\
\hline Pioglitazone, n (\%) & $6(3.2)$ & $0(0.0)$ & NS \\
\hline Glinide, n (\%) & $0(0.0)$ & $0(0.0)$ & NS \\
\hline Insulin, n (\%) & $2(1.1)$ & $0(0.0)$ & NS \\
\hline Inotropic agents, n (\%) & $4(2.1)$ & $0(0.0)$ & NS \\
\hline
\end{tabular}

Data are presented as number (percentage)

$L M T$ left main coronary trunk, $L A D$ left anterior descending coronary artery, $L C X$ left circumflex coronary artery, $R C A$ right coronary artery, $P C I$ percutaneous coronary intervention, $B M S$ bare metal stent, $D E S$ drug eluting stent, $P O B A$ percutaneous old balloon angioplasty, $C A B G$ coronary artery bypass grafting, $A C E$ angiotensin converting enzyme, $A R B$ angiotensin-II receptor blocker, DPP-4 dipeptidyl peptidase-4

* Comparisons between the survivor and the cardiac death groups

categorized into two groups based on median 1,5-AG level $(18.5 \mu \mathrm{g} / \mathrm{ml})$. Event-free survival rate was significantly lower in the low 1,5 -AG group than in their counterparts with high $1,5-\mathrm{AG}$ ( $p=0.02$, Fig. 2).

Univariate Cox regression analyses revealed that 1,5AG level, age, gender, left ventricular ejection fraction, HbA1c level, eGFR, brain natriuretic peptide level, albumin level, hemoglobin level, multi-vessel disease, and diuretic or statin administration at discharge were associated with long-term cardiac mortality. After accounting for confounding variables, 1,5-AG was found to be significantly associated with long-term cardiac mortality $(1 \mu \mathrm{g} / \mathrm{ml}$ increase; $\mathrm{HR}, 0.76 ; 95 \% \mathrm{CI}, 0.41-0.98 ; p=0.03$, Table 3).

\section{Discussion}

The present study demonstrated that low 1,5-AG levels, but not HbA1c levels, could predict long-term mortality in ACS patients with HbA1c level $<7.0 \%$. 


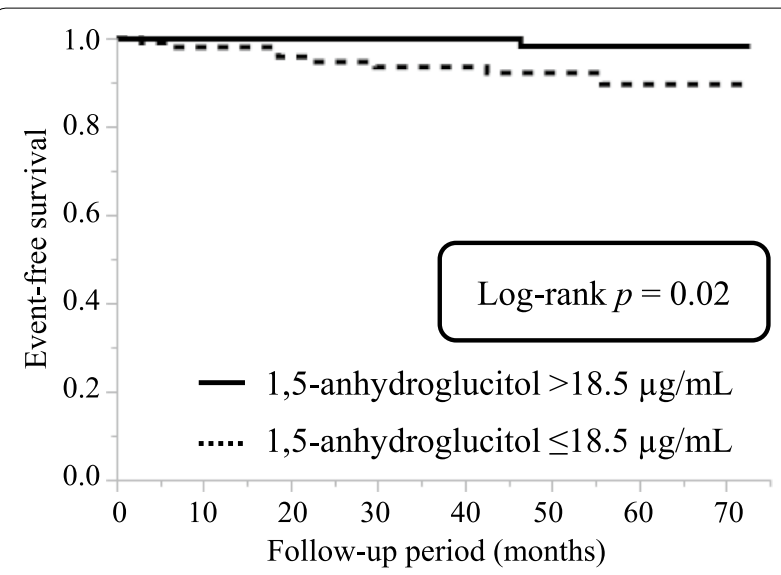

Fig. 2 Event-free survival curve for cardiac death in patients with acute coronary syndrome. Unadjusted cumulative event rate for the primary endpoint (cardiac death) was estimated using the KaplanMeier method and compared between groups using the log-rank test. We defined the cut-off value as the median level of 1,5-anhydroglucitol $(18.5 \mu \mathrm{g} / \mathrm{ml})$

Treatment of DM in adult patients is done with a goal to achieve HbA1c level $<7.0 \%$, which is associated with prevention of DM-associated complications. However, macrovascular disease cannot be completely prevented even under the above treatment conditions [34-39]. The United Kingdom prospective Diabetes Study (UKPDS) showed that intensive blood-glucose control decreases risk of microvascular complications by $25 \%$, but not that of macrovascular disease in patients with type 2 DM. Further, all intensive treatments were found to increase the risk of hypoglycemia [34]. However, during the 10-year post-trial follow up, a continuous decrease in microvascular complications, risk of all-cause death, and myocardial infarction were seen over time in the intensive blood-glucose control group [40]. The Action to Control Cardiovascular Risk in Diabetes (ACCORD) study demonstrated that the use of intensive therapy to target normal HbA1c levels increased mortality and did not significantly reduce major cardiovascular events as compared with standard therapy [35]. The Action in Diabetes and Vascular Disease: Preterax and Diamicron Modified Release Controlled Evaluation (ADVANCE) showed that a strategy of intensive glucose control lowered $\mathrm{HbA} 1 \mathrm{c}$ to $6.5 \%$ and reduced the incidence of microvascular events, but did not significantly reduce the incidence of major macrovascular events or death [36]. Comprehensive evaluation in addition to that of $\mathrm{HbA1c}$ may be necessary for prevention of macrovascular disease, especially in patients with HbA1c levels $<7.0 \%$.

The HbA1c level reflects the average blood glucose level over the past 2 months and can be confounded in patients with anemia, hemoglobinopathy, and renal dysfunction [41]. The 1,5-AG level is more reflective of short-term glycemic status compared with the HbA1c level. Moreover, 1,5-AG level reflects postprandial hyperglycemia and glycemic variability, which are not captured by HbA1c measurement $[19,42]$.

A previous cohort study reported that postprandial hyperglycemia was associated with cardiovascular disease and death [43, 44]. The Diabetes Epidemiology: Collaborative analysis of Diagnostic criteria in Europe (DECODE) study showed that postprandial hyperglycemia was a better predictor of mortality in subjects with newly diagnosed DM and in those with impaired glucose tolerance than fasting glucose [43]. Previous studies

Table 3 Univariate and multivariate Cox regression analyses of cardiac death

\begin{tabular}{|c|c|c|c|c|c|c|}
\hline & \multicolumn{3}{|c|}{ Univariate } & \multicolumn{3}{|c|}{ Multivariate } \\
\hline & HR & $95 \% \mathrm{Cl}$ & $p$-value & HR & $95 \% \mathrm{Cl}$ & $p$-value \\
\hline Age, 1 year increase & 1.10 & $1.03-1.18$ & $<0.01$ & 1.25 & $1.06-1.65$ & $<0.01$ \\
\hline Male, yes & 1.51 & $0.28-28.0$ & 0.7 & 0.07 & $0.01-4.76$ & NS \\
\hline Body mass index, $1 \mathrm{~kg} / \mathrm{m}^{2}$ increase & 0.83 & $0.66-1.03$ & 0.09 & 0.89 & $0.57-1.28$ & NS \\
\hline LVEF $>60 \%$, yes & 0.13 & $0.01-0.72$ & 0.02 & 0.02 & $0.01-0.42$ & 0.01 \\
\hline HbA1c, $0.1 \%$ increase & 1.17 & $1.03-1.34$ & 0.02 & 1.13 & $0.92-1.42$ & NS \\
\hline eGFR, $1 \mathrm{ml} / \mathrm{min} / 1.73 \mathrm{~m}^{2}$ increase & 0.96 & $0.92-0.99$ & 0.04 & 0.88 & $0.76-0.97$ & $<0.01$ \\
\hline BNP $>100 \mathrm{pg} / \mathrm{ml}$, yes & 4.01 & $1.06-19.0$ & 0.04 & 0.32 & $0.01-5.20$ & NS \\
\hline Albumin, $0.1 \mathrm{~g} / \mathrm{dl}$ increase & 0.86 & $0.77-0.98$ & 0.02 & 1.13 & $0.90-1.54$ & NS \\
\hline Hemoglobin, $1 \mathrm{~g} / \mathrm{dl}$ increase & 0.65 & $0.46-0.92$ & 0.02 & 1.06 & $0.57-2.16$ & NS \\
\hline Multi-vessel disease, yes & 5.28 & $0.97-98.0$ & 0.06 & 5.52 & $0.07-2710$ & NS \\
\hline Diuretic usage, yes & 4.60 & $1.22-18.6$ & 0.03 & 0.17 & $0.01-2.19$ & NS \\
\hline Statin usage, yes & 0.23 & $0.06-1.09$ & 0.06 & 0.004 & $0.01-0.11$ & $<0.01$ \\
\hline 1,5-AG, $1 \mu \mathrm{g} / \mathrm{ml}$ increase & 0.88 & $0.79-0.97$ & $<0.01$ & 0.76 & $0.41-0.98$ & 0.03 \\
\hline
\end{tabular}


have also reported that 1,5-AG levels were associated with atherosclerosis and cardiovascular disease [22, 4548]. Fujiwara et al. reported that 1,5-AG was associated with the presence of de novo coronary artery disease in 227 consecutive patients with HbA1c levels $<7.0 \%$ [46]. Selvin et al. reported that among 11,106 participants in the Atherosclerosis Risk in Communities study, subjects with DM and 1,5-AG levels $<6.0 \mu \mathrm{g} / \mathrm{ml}$ had an increased risk of coronary artery disease, stroke, heart failure, and death compared to subjects with 1,5-AG levels $\geq 6.0 \mu \mathrm{g} /$ $\mathrm{ml}$ and no history of DM [47]. In the Suita study, a cohort study in Japan, Watanabe et al. reported that adjusted HRs of all cardiovascular diseases in men increased linearly with decreasing $1,5-\mathrm{AG}$, and that HR was 2.22 in the category with lowest $1,5-\mathrm{AG}(\leq 14.0 \mu \mathrm{g} / \mathrm{ml})$ compared to the category with highest 1,5 -AG $(\geq 24.5 \mu \mathrm{g} / \mathrm{ml})$ in 2095 initially healthy Japanese men without a history of coronary artery disease or stroke [48]. We have recently reported that low and exacerbated levels of 1,5-AG were associated with cardiovascular events in patients with HbA1c $<7.0 \%$ who underwent first-time elective percutaneous coronary intervention [23]. The present study is the first to report that 1,5-AG levels are significantly associated with cardiac mortality in ACS patients with HbAlc $<7.0 \%$.

The clear cut-off value of 1,5-AG for diagnosis of DM remains unclear. This study population and events were relatively small, therefore, the cut-off value was defined using the median of 1,5-AG levels. The 1,5-AG levels are reported to be influenced by diet and race and are relatively lower in the Japanese than in Americans [41, 49]. Further studies are required in order to determine the cut-off values for cardiovascular events in patients with different conditions and of various races [50].

This study had several limitations. First, the study was conducted in a single institution and the study population was relatively small. Studies with a larger sample size and racial diversity will be more effective in evaluating the association between 1,5-AG levels and prognosis in ACS patients with $\mathrm{HbA} 1 \mathrm{c}<7.0 \%$. Second, we were unable to determine all clinical characteristics with an effect on 1,5AG levels (e.g., renal glycosuria). Third, we did not perform the $75 \mathrm{~g}$ oral glucose tolerance test in patients who were not previously diagnosed with DM. This may have led to underestimation of the number of patients with DM. Finally, the levels of glycoalbumin were not measured in this study. However, a previous study reported that 1,5-AG was independently associated with de-novo coronary artery disease, whereas HbA1c and glycoalbumin were not independently associated with the disease [46]. In concordance with the previous study, multivariate Cox regression analysis showed that 1,5-AG but not $\mathrm{HbA1c}$ was significantly associated with long-term cardiac mortality in the present study. We believe that the 1,5-AG level, which is considered a clinical marker of postprandial hyperglycemia, may be a useful marker for risk stratification in patients with coronary artery disease. Further studies will be required to confirm these findings.

\section{Conclusion}

Low 1,5-AG levels, which indicate postprandial hyperglycemia, predicted long-term cardiac mortality in ACS patients with $\mathrm{HbA} 1 \mathrm{c}<7.0 \%$.

\section{Abbreviations \\ 1,5-AG: 1,5-anhydroglucitol; ACS: acute coronary syndrome; Cl: confidence interval; DM: diabetes mellitus; eGFR: estimated glomerular filtration rate; HbA1c: hemoglobin A1c; HR: hazard ratio. \\ Authors' contributions \\ SO participated in the planning of the study, analysis, and draft the manu- script. KS contributed to the planning of the study and at all stages drafted the manuscript. TM, ST, YS, MS, AM, To K, Takao K, TA, SS, ES, and MH were involved in recruiting the study subjects, data analysis, and discussing of results. HI, Takat $\mathrm{K}$, and $\mathrm{KM}$ were involved in discussing results. HD contributed to the planning of the experiment and discussion of the results, as well as to the supervision of the study. All authors read and approved the final manuscript.}

\section{Acknowledgements \\ The authors wish to thank each of the participant for the data provided, and Enago (http://www.enago.jp) for English language review.}

\section{Competing interests}

The authors declare that they have no competing interests.

\section{Availability of data and materials}

The datasets during and/or analyzed during the current study are available from the corresponding author with reasonable request.

\section{Consent for publication}

Participants were informed of data sharing with their name and identity hidden per consent.

\section{Ethics approval and consent to participate}

This study was approved by the institutional review board at the Juntendo University Hospital. All participants provided written informed consent.

\section{Funding}

This study was partially supported by a High Technology Research Center Grant from the Ministry of Education, Culture, Sports, Science, and Technology of Japan.

\section{Publisher's Note}

Springer Nature remains neutral with regard to jurisdictional claims in published maps and institutional affiliations.

Received: 27 September 2017 Accepted: 10 November 2017

Published online: 21 November 2017

\section{References}

1. Bonds DE, Miller ME, Bergenstal RM, Buse JB, Byington RP, Cutler JA, Dudl RJ, Ismail-Beigi F, Kimel AR, Hoogwerf B, et al. The association between symptomatic, severe hypoglycaemia and mortality in type 2 diabetes: retrospective epidemiological analysis of the ACCORD study. BMJ. 2010;340:b4909. 
2. De Caterina R, Madonna R, Sourij H, Wascher T. Glycaemic control in acute coronary syndromes: prognostic value and therapeutic options. Eur Heart J. 2010;31(13):1557-64.

3. Daida H, Miyauchi K, Ogawa H, Yokoi H, Matsumoto M, Kitakaze M, Kimura T, Matsubara T, Ikari Y, Kimura K, et al. Management and 2-year long-term clinical outcome of acute coronary syndrome in Japan. Circ J. 2013;77(4):934-43.

4. Hiki M, Shimada K, Kiyanagi T, Fukao K, Hirose K, Ohsaka H, Fukushima Y, Kume A, Matsumori R, Sumiyoshi K, et al. Single administration of alpha-glucosidase inhibitors on endothelial function and incretin secretion in diabetic patients with coronary artery disease-Juntendo University trial: effects of miglitol on endothelial vascular reactivity in type 2 diabetic patients with coronary heart disease (J-MACH). Circ J. 2010;74(7):1471-8

5. Mukai N, Ninomiya T, Hata J, Hirakawa Y, Ikeda F, Fukuhara M, Hotta T, Koga M, Nakamura U, Kang D, et al. Association of hemoglobin A1c and glycated albumin with carotid atherosclerosis in community-dwelling Japanese subjects: the Hisayama Study. Cardiovasc Diabetol. 2015;14:84

6. Bots SH, van der Graaf Y, Nathoe HM, de Borst GJ, Kappelle JL, Visseren FL, Westerink J. The influence of baseline risk on the relation between $\mathrm{HbA} 1 \mathrm{c}$ and risk for new cardiovascular events and mortality in patients with type 2 diabetes and symptomatic cardiovascular disease. Cardiovasc Diabetol. 2016;15(1):101.

7. Goto A, Noda M, Matsushita Y, Goto M, Kato M, Isogawa A, Takahashi Y, Kurotani K, Oba S, Nanri A, et al. Hemoglobin A1c levels and the risk of cardiovascular disease in people without known diabetes: a populationbased cohort study in Japan. Medicine. 2015;94(17):e785.

8. Selvin E, Steffes MW, Zhu H, Matsushita K, Wagenknecht L, Pankow J, Coresh J, Brancati FL. Glycated hemoglobin, diabetes, and cardiovascular risk in nondiabetic adults. N Engl J Med. 2010;362(9):800-11.

9. Sakamoto M, Nishimura R, Irako T, Tsujino D, Ando K, Utsunomiya K. Comparison of vildagliptin twice daily vs. sitagliptin once daily using continuous glucose monitoring (CGM): crossover pilot study (J-VICTORIA study). Cardiovasc Diabetol. 2012;11:92.

10. Haffner SM, Lehto S, Rönnemaa T, Pyörälä K, Laakso M. Mortality from coronary heart disease in subjects with type 2 diabetes and in nondiabetic subjects with and without prior myocardial infarction. N Engl J Med. 1998;339(4):229-34.

11. American Diabetes Association. 5. Glycemic Targets. Diabetes Care. 2016:39:S39-46.

12. Inzucchi SE, Bergenstal RM, Buse JB, Diamant M, Ferrannini E, Nauck M, Peters AL, Tsapas A, Wender R, Matthews DR. Management of hyperglycaemia in type 2 diabetes, 2015: a patient-centred approach. Update to a position statement of the American Diabetes Association and the European association for the study of diabetes. Diabetologia. 2015:58(3):429-42.

13. Sakurai M, Saitoh $S$, Miura K, Nakagawa H, Ohnishi H, Akasaka H, Kadota A, Kita Y, Hayakawa T, Ohkubo T, et al. HbA1c and the risks for all-cause and cardiovascular mortality in the general Japanese population: NIPPON DATA90. Diabetes Care. 2013;36(11):3759-65.

14. Miyazaki T, Shimada K, Iwama Y, Kume A, Sumiyoshi K, Sato Y, Ohmura H, Watanabe $Y$, Mokuno H, Daida H. Insulin response to oral glucose load is associated with coronary artery disease in subjects with normal glucose tolerance. J Atheroscler Thromb. 2008;15:6-12.

15. Tominaga M, Equchi $H$, Manaka H, Igarashi K, Kato T, Sekikawa A. Impaired glucose tolerance is a risk factor for cardiovascular disease, but not impaired fasting glucose. The Funagata Diabetes Study. Diabetes Care. 1999;22(6):920-4

16. Fukao K, Shimada K, Hiki M, Kiyanagi T, Hirose K, Kume A, Ohsaka H, Matsumori R, Kurata T, Miyazaki T, et al. Effects of calcium channel blockers on glucose tolerance, inflammatory state, and circulating progenitor cells in non-diabetic patients with essential hypertension: a comparative study between azelnidipine and amlodipine on glucose tolerance and endothelial function-a crossover trial (AGENT). Cardiovasc Diabetol. 2011;10:79.

17. Juraschek SP, Miller ER 3rd, Appel LJ, Christenson RH, Sacks FM, Selvin E. Effects of dietary carbohydrate on 1,5-anhydroglucitol in a population without diabetes: results from the OmniCarb trial. Diabet Med. 2017;34(10):1407-13.

18. McGill JB, Cole TG, Nowatzke W, Houghton S, Ammirati EB, Gautille T, Sarno MJ. Circulating 1,5-anhydroglucitol levels in adult patients with diabetes reflect longitudinal changes of glycemia. Diabetes Care. 2004;27(8):1859-65.

19. Dungan KM, Buse JB, Largay J, Kelly MM, Button EA, Kato S, Wittlin S. 1,5-Anhydroglucitol and postprandial hyperglycemia as measured by continuous glucose monitoring system in moderately controlled patients with diabetes. Diabetes Care. 2006;29(6):1214-9.

20. Torimoto K, Okada Y, Mori H, Tanaka Y. Low levels of 1,5-anhydroD-glucitol are associated with vascular endothelial dysfunction in type 2 diabetes. Cardiovasc Diabetol. 2014;13:99.

21. Ma X, Hu X, Zhou J, Hao Y, Luo Y, Lu Z, Bao Y, Jia W. Glycated albumin is more closely correlated with coronary artery disease than 1,5-anhydroglucitol and glycated hemoglobin A1c. Cardiovasc Diabetol. 2015;14:16

22. Ikeda N, Hara H, Hiroi Y. 1,5-Anhydro-D-glucitol predicts coronary artery disease prevalence and complexity. J Cardiol. 2014;64(4):297-301.

23. Takahashi S, Shimada K, Miyauchi K, Miyazaki T, Sai E, Ogita M, Tsuboi S, Tamura H, Okazaki S, Shiozawa T, et al. Low and exacerbated levels of 1,5-anhydroglucitol are associated with cardiovascular events in patients after first-time elective percutaneous coronary intervention. Cardiovasc Diabetol. 2016;15(1):145.

24. Mauri L, Hsieh W-h, Massaro JM, Ho KKL, D’Agostino R, Cutlip DE. Stent thrombosis in randomized clinical trials of drug-eluting stents. N Engl J Med. 2007:356(10):1020-9.

25. Japanese Society of Nephrology. Evidence-based clinical practice guideline for CKD 2013. Clin Exp Nephrol. 2014;18(3):346-423.

26. Amsterdam EA, Wenger NK, Brindis RG, Casey DE, Ganiats TG, Holmes DR, Jaffe AS, Jneid H, Kelly RF, Kontos MC, et al. 2014 AHA/ACC guideline for the management of patients with non-ST-elevation acute coronary syndromes. Rep Am Coll Cardiol. 2014;130(25):e344-426.

27. Antman EM, Anbe DT, Armstrong PW, Bates ER, Green LA, Hand M, Hochman JS, Krumholz HM, Kushner FG, Lamas GA, et al. ACC/AHA guidelines for the management of patients with ST-Elevation myocardial infarction-executive summary. Rep Am Coll Cardiol. 2004;44(3):671-719.

28. Naito R, Miyauchi K, Konishi H, Tsuboi S, Ogita M, Dohi T, Kasai T, Tamura H, Okazaki S, Isoda K, et al. Gender difference in long-term clinical outcomes following percutaneous coronary intervention during 1984-2008. Atherosclerosis. 2016;247:105-10.

29. Vieira RDO, Hueb W, Gersh BJ, Lima EG, Pereira AC, Rezende PC, Garzillo $C L$, Hueb AC, Favarato D, Soares PR, et al. Effect of complete revascularization on 10-year survival of patients with stable multivessel coronary artery disease, MASS II Trial. Circulation. 2012;126(11):S158-63.

30. Shimamoto K, Ando K, Fujita T, Hasebe N, Higaki J, Horiuchi M. The Japanese society of hypertension guidelines for the management of hypertension (JSH 2014). Hypertens Res. 2014;37(4):253.

31. Matsuo S, Imai E, Horio M, Yasuda Y, Tomita K, Nitta K, Yamagata K, Tomino Y, Yokoyama H, Hishida A. Revised equations for estimated GFR from serum creatinine in Japan. Am J Kidney Dis. 2009;53(6):982-92.

32. William TF, Robert IL, Donald SF. Estimation of the concentration of lowdensity lipoprotein cholesterolin plasma, without use of the preparative ultracentrifuge. Clin Chem. 1972;18(6):499-502.

33. Miyazaki T, Shimada K, Miyauchi K, Kume A, Tanimoto K, Kiyanagi T, Sumiyoshi K, Hiki M, Mokuno H, Okazaki S, et al. Effects of fenofibrate on lipid profiles, cholesterol ester transfer activity, and in-stent intimal hyperplasia in patients after elective coronary stenting. Lipids Health Dis. 2010;9:122.

34. UK Prospective Diabetes Study Group. Intensive blood-glucose control with sulphonylureas or insulin compared with conventional treatment and risk of complications in patients with type 2 diabetes (UKPDS 33). Lancet. 1998;352(9131):837-53.

35. Gerstein HC, Miller ME, Byington RP, Goff DC Jr, Bigger JT, Buse JB, Cushman WC, Genuth S, Ismail-Beigi F, Grimm RH Jr, et al. Effects of intensive glucose lowering in type 2 diabetes. N Engl J Med. 2008;358(24):2545-59.

36. The ADVANCE Collaborative Group. Intensive blood glucose control and vascular outcomes in patients with type 2 diabetes. N Engl J Med. 2008;358(24):2560-72.

37. Kawasaki R, Tanaka S, Tanaka S, Yamamoto T, Sone H, Ohashi Y, Akanuma Y, Yamada N, Yamashita H, Japan Diabetes Complications Study Group. Incidence and progression of diabetic retinopathy in Japanese adults with type 2 diabetes: 8 year follow-up study of the Japan Diabetes Complications Study (JDCS). Diabetologia. 2011;54(9):2288-94.

38. Sone H, Tanaka S, Tanaka S, limuro S, Oida K, Yamasaki Y, Oikawa S, Ishibashi S, Katayama S, Ohashi Y, et al. Serum level of triglycerides is a potent risk factor comparable to LDL cholesterol for coronary heart 
disease in Japanese patients with type 2 diabetes: subanalysis of the Japan Diabetes Complications Study (JDCS). J Clin Endocrinol Metab. 2011;96(11):3448-56.

39. Duckworth W, Abraira C, Moritz T, Reda D, Emanuele N, Reaven PD, Zieve FJ, Marks J, Davis SN, Hayward R, et al. Glucose control and vascular complications in veterans with type 2 diabetes. N Engl J Med. 2009;360(2):129-39

40. Holman RR, Paul SK, Bethel MA, Matthews DR, Neil HA. 10-year followup of intensive glucose control in type 2 diabetes. N Engl J Med. 2008;359(15):1577-89.

41. Dungan KM. 1,5-Anhydroglucitol (GlycoMark) as a marker of shortterm glycemic control and glycemic excursions. Expert Rev Mol Diagn. 2008:8(1):9-19.

42. Yamanouchi T, Ogata N, Tagaya T, Kawasaki T, Sekino N, Funato H, Akaoka L, Miyashita H. Clinical usefulness of serum 1,5-anhydroglucitol in monitoring glycaemic control. Lancet. 1996;347(9014):1514-8.

43. The DECODE study group on behalf of the European Diabetes Epidemiology Group. Glucose tolerance and mortality: comparison of WHO and American diabetic association diagnostic criteria. Lancet. 1999:354(9179):617-21.

44. Stratton IM, Adler Al, Neil HAW, Matthews DR, Manley SE, Cull CA, Hadden D, Turner RC, Holman RR. Association of glycaemia with macrovascular and microvascular complications of type 2 diabetes (UKPDS 35): prospective observational study. BMJ. 2000;321(7258):405-12.

45. Sato T, Kameyama T, Inoue H. Association of reduced levels of serum 1,5-anhydro-D-glucitol with carotid atherosclerosis in patients with type 2 diabetes. J Diabetes Complicat. 2014;28(3):348-52.

46. Fujiwara T, Yoshida M, Yamada H, Tsukui T, Nakamura T, Sakakura K, Wada $\mathrm{H}$, Arao K, Katayama T, Funayama H, et al. Lower 1,5-anhydroglucitol is associated with denovo coronary artery disease in patients at high cardiovascular risk. Heart Vessels. 2015;30(4):469-76.

47. Selvin E, Rawlings A, Lutsey P, Maruthur N, Pankow JS, Steffes M, Coresh J. Association of 1,5-anhydroglucitol with cardiovascular disease and mortality. Diabetes. 2016;65(1):201-8.

48. Watanabe M, Kokubo Y, Higashiyama A, Ono Y, Miyamoto Y, Okamura T. Serum 1,5-anhydro-D-glucitol levels predict first-ever cardiovascular disease: an 11-year population-based cohort study in Japan, the Suita study. Atherosclerosis. 2011;216(2):477-83.

49. Kim WJ, Park CY. 1,5-Anhydroglucitol in diabetes mellitus. Endocrine. 2013:43(1):33-40.

50. Malkan UY, Gunes G, Corakci A. Rational diagnoses of diabetes: the comparison of 1,5-anhydroglucitol with other glycemic markers. SpringerPlus. 2015; $4: 587$

\section{Submit your next manuscript to BioMed Central and we will help you at every step:}

- We accept pre-submission inquiries

- Our selector tool helps you to find the most relevant journal

- We provide round the clock customer support

- Convenient online submission

- Thorough peer review

- Inclusion in PubMed and all major indexing services

- Maximum visibility for your research

Submit your manuscript at www.biomedcentral.com/submit 